\title{
Hospital spending in real terms and public choice
}

\author{
NICK BOSANQUET
}

Statistics on health expenditure "at constant prices" remain conspicuous for their inadequacy. Officially, figures are quickly available only in a highly aggregate form. Such figures for current and capital spending are published in the National Income Blue Book and are given a grading of B ( $\pm 3 \%$ to $10 \%)$ by the Central Statistical Office. ${ }^{1}$ On a disaggregated basis figures are available on expenditure by client group but these are inevitably slow to materialise and have undergone a long process of adjustment.

Against this background of inadequate information, changes in expenditure at constant prices still remain a focus for debate and for decision by governments. Debate continues on the issue of whether Britain should raise spending in real terms relative to other countries. Decisions are made every year about how much to spend on the NHS. In other countries, such as the Netherlands or the United States, the total spent on health services is the outcome of many separate decisions taken by insurance funds and by large hospitals. It is not a real decision taken by government as such. In Britain the central Government has to make such a definite decision and in recent years it has also been showing much more concern about the division of this spending between regions and client groups.

In this paper I have tried to provide some new information about the real meaning of changes in expenditure at constant prices. Governments have had freedom to vary this within a range of -2 to $+5 \%$. What have such variations meant in terms of changes in spending at the local level ? It could be that all items in health spending would show roughly the same change or there could be considerable differences in the growth of some types of spending.

Our main focus is on long-term changes in the balance of spending since the 1960s and thus inevitably on hospital service expenditure. It is possible to produce a consistent series for hospital service expenditure using the older accounting methods: it would be much more difficult to produce a series for the NHS as constituted since 1974 on a client group basis. The hospital service is in any case by far the largest item in spending and the one that showed the fastest growth before 1974 .

Official figures for total revenue expenditure at constant prices are produced by using two main deflators: a single index of salaries and wages together with the health services (formerly hospital services) price index. The aim here is to produce more detailed figures. Figures on staff numbers (in whole-time equivalents) were used to adjust each of the main types of staff expenditure. This is a better way of getting at the true change at constant prices as it excludes the relative price effect. The manpower figures, however, are only available with such a long delay that they could not be used to produce the CSO's figures. For other types of spending the hospital price index was used together with the independent index of drug prices.

\footnotetext{
Department of Social Sciences and Humanities, The City University, London EC1V OHB

NICK BOSANQUET, BA, MSC, lecturer in economics
}

\section{Switch from support functions}

The main results for the period 1963-73 show a surprisingly strong switch of spending away from support functions towards medical and technical staff and towards costs associated with active medical treatment. This is partly to be expected in a service in which duration of stay was falling and more active medical treatment and more intensive nursing care being carried out. But against general impressions of the momentum of spending, the lack of increase in spending on most support functions stands out.

Over the whole period spending on medical staff grew by $45 \%$ and on professional and technical staff by $61 \%$ (table I). Spending on ancillary staff grew by $7 \%$ and spending on provisions fell, while that on drugs and dressings rose by $71 \%$. There was only modest growth in spending on services and maintenance.

TABLE I-Hospital service expenditure at constant 1963 prices (England and Wales)

\begin{tabular}{lcc}
\hline & 1963 & 1973 \\
\hline Medical and dental staff & 100 & $145 \cdot 5$ \\
Nursing and midwifery staff & 100 & 136.9 \\
Professional and technical staff & 100 & $161 \cdot 0$ \\
Ancillary staff & 100 & $107 \cdot 2$ \\
Administrative and clerical staff & 100 & $157 \cdot 1$ \\
Total & 100 & $128 \cdot 1$ \\
Provisions & 100 & 96.9 \\
Drugs and dressings & 100 & $171 \cdot 2$ \\
Medical and surgical equipment and appliances & 100 & 187.5 \\
Services and maintenance & 100 & $121 \cdot 4$ \\
Grand total: All hospital current spending & 100 & $128 \cdot 9$ \\
All NHS current spending: Blue Book* & 100 & 136.3 \\
\hline
\end{tabular}

*At constant 1970 prices.

TABLE II-Expenditure at constant prices, hospital service, percentages of total (England and Wales)

\begin{tabular}{lrr}
\hline & 1963 & 1973 \\
\hline Medical and dental staff & $12 \cdot 0$ & $13 \cdot 3$ \\
Nursing and midwifery staff & $27 \cdot 8$ & $29 \cdot 0$ \\
Professional and technical staff & $3 \cdot 1$ & $3 \cdot 9$ \\
Drugs and dressings & $3 \cdot 7$ & $4 \cdot 8$ \\
Medical and surgical equipment and appliances & $4 \cdot 7$ & $6 \cdot 8$ \\
Support services & $23 \cdot 6$ & $19 \cdot 3$ \\
Ancillary staff & $4 \cdot 3$ & $5 \cdot 2$ \\
Administrative and clerical staff & $8 \cdot 3$ & $6 \cdot 1$ \\
Provisions & $12 \cdot 4$ & $11 \cdot 5$ \\
Services and maintenance & & \\
\hline
\end{tabular}

The difference in growth between the overall figures and those of the Blue Book is not surprising. The Blue Book figures reflect the increasingly strong "relative price effect." But the extent of the restraint made in spending on support functions is certainly surprising. They were strong enough to bring about significant changes in the composition of total spending. Thus spending on support functions fell from $48.6 \%$ of total expenditure in 1963 to $42.1 \%$ in 1973 (table II).

On a year-to-year basis spending on materials inputs showed slightly greater variation than expenditure on staff (table III) 
TABLE III-NHS spending at constant prices, percentage changes from year to year, 1963-73 (England and Wales)

\begin{tabular}{|c|c|c|c|c|c|c|c|c|c|c|c|}
\hline & $1963-4$ & $1964-5$ & $1965-6$ & 1966-7 & $1967-8$ & 1968-9 & $1969-70$ & $1970-1$ & $1971-2$ & $1972-3$ & $\begin{array}{c}\text { Coefficient } \\
\text { of } \\
\text { variation } \\
\%\end{array}$ \\
\hline $\begin{array}{l}\text { Medical and dental staff } \\
\text { Nursing and midwifery staff } \\
\text { Professional and technical staff } \\
\text { Ancillary staff } \\
\text { Administrative and clerical staff } \\
\text { Staff total } \\
\text { Provisions } \\
\text { Drugs and dressings } \\
\text { Services and maintenance } \\
\text { Medical and surgical appliances and equipment } \\
\quad \text { Total } \\
\text { Grand total }\end{array}$ & $\begin{array}{l}+2 \cdot 23 \\
+2 \cdot 22 \\
+4 \cdot 21 \\
+0.85 \\
+2 \cdot 75 \\
+1 \cdot 82 \\
+1.97 \\
+6 \cdot 42 \\
+4.55 \\
+6.33 \\
+4.34 \\
+2.40\end{array}$ & $\begin{array}{l}+2.93 \\
+4.72 \\
+5 \cdot 17 \\
+0.22 \\
+4.88 \\
+2.91 \\
-1.94 \\
+6.13 \\
-11.72 \\
-3.14 \\
-5.26 \\
+0.97\end{array}$ & $\begin{array}{l}+3 \cdot 38 \\
+4 \cdot 11 \\
+5 \cdot 05 \\
+2 \cdot 90 \\
+4 \cdot 64 \\
+3 \cdot 70 \\
-2 \cdot 41 \\
+4 \cdot 69 \\
+0 \cdot 26 \\
+6 \cdot 39 \\
+0.96 \\
+3 \cdot 10\end{array}$ & $\begin{array}{l}+4.54 \\
+3.36 \\
+5.00 \\
+2.25 \\
+3.03 \\
+3.14 \\
-0.64 \\
+7.51 \\
+6.85 \\
+11.05 \\
+5.61 \\
+3.67\end{array}$ & $\begin{array}{l}+4 \cdot 13 \\
+0.82 \\
+3.30 \\
-0.92 \\
+2 \cdot 20 \\
+0.54 \\
-3.36 \\
+3.42 \\
-1.58 \\
+6.02 \\
+0.15 \\
+0.45\end{array}$ & $\begin{array}{l}+3.63 \\
+1.90 \\
+4.90 \\
+0.15 \\
+4.71 \\
+1.71 \\
+3.54 \\
+4.50 \\
+3.97 \\
+6.80 \\
+2.78 \\
+1.95\end{array}$ & $\begin{array}{r}+2.53 \\
+2.83 \\
+5.82 \\
+0.72 \\
+4.59 \\
+2.36 \\
+1.61 \\
+9.61 \\
+4.31 \\
+10.65 \\
+5.83 \\
+3.13\end{array}$ & $\begin{array}{l}+5.41 \\
+4.20 \\
+4.65 \\
+2.91 \\
+5.24 \\
+3.89 \\
-4.09 \\
-1.39 \\
+7.67 \\
+4.76 \\
+2.84 \\
+3.65\end{array}$ & $\begin{array}{r}+5.09 \\
+6.57 \\
+5.82 \\
+0.40 \\
+6.93 \\
+4.27 \\
+0.56 \\
+5.54 \\
+5.40 \\
+11.38 \\
+5.70 \\
+4.60\end{array}$ & $\begin{array}{l}+4.36 \\
+1.29 \\
+4.87 \\
-2.53 \\
+7.39 \\
+0.84 \\
+9.06 \\
+9.25 \\
+1.91 \\
+5.40 \\
+5.34 \\
+1.87\end{array}$ & $\begin{array}{r}12 \cdot 17 \\
9 \cdot 90 \\
15 \cdot 06 \\
31 \cdot 85 \\
14 \cdot 06 \\
8 \cdot 64 \\
4 \cdot 74 \\
16 \cdot 12 \\
9 \cdot 20 \\
21 \cdot 71 \\
10 \cdot 27 \\
9 \cdot 09\end{array}$ \\
\hline
\end{tabular}

Spending on medical, technical, and administrative staff showed a steady rise with low coefficients of variation. Ancillary staff spending showed high variation around a trend of slow growth. Expenditure on ancillary staff has a coefficient of variation of $32 \%$ as compared with $12 \%$ for expenditures on medical staff. We can illustrate the actual impact of changes in aggregate expenditure in terms of the "down" of 1967-9 and of the "up" of 1972. In 1967-9 spending on technical and medical staff continued to grow. Outlays on ancillary staff fell and there was a decisive braking back of growth in funds for nurse staffing. In 1972 there was a push in all areas except for ancillary staff. This suggests that a large increase in NHS spending relative to trend will mainly lead to an increase in the nursing input and to more spending on support services. Expenditure on support services will oscillate between decline and slow growth while funds for nurse staffing will show some swings in rates of growth. The medical and technical inputs will go on growing in good times and in bad.

For the hospital service the pattern shows more change in accounting methods than in substance since 1974 (table IV). The TABLE IV-Changes in hospital service expenditure at constant
1974 prices (England)

\begin{tabular}{lrr}
\hline & 1974 & 1977 \\
\hline Medical and dental staff & 100 & $110 \cdot 9$ \\
Nursing and midwifery staff & 100 & $112 \cdot 1$ \\
Professional and technical staff & 100 & $123 \cdot 5$ \\
Ancillary staff & 100 & $105 \cdot 7$ \\
Administrative and clerical staff & 100 & $120 \cdot 4$ \\
Total & 100 & $112 \cdot 1$ \\
Medical and surgical supplies & 100 & $109 \cdot 0$ \\
Administration & 100 & $108 \cdot 2$ \\
Medical records & 100 & $94 \cdot 7$ \\
Catering, etc & 100 & $96 \cdot 6$ \\
Estate management & 100 & $110 \cdot 0$ \\
Grand total: All hospital current spending & 100 & 106.0 \\
All NHS current spending: Blue Book* & 100 & $110 \cdot 5$ \\
\hline
\end{tabular}

*At constant 1975 prices.

medical and technical inputs have gone on growing with a particularly notable surge in spending on professional staff matched only by administrative and clerical staffs. There was economy in catering but estate management showed a rather different story, with more growth, perhaps as the new authorities became aware of the poor state of much of their property. The NHS is continuing to finance some growth in technical and medical inputs by economising on most support services.

It might be argued that the growth within medical staffing had been mainly in the "cinderella" specialties such as psychiatry and geriatric medicine. The evidence for 1963-73 does not suggest this. The number of geriatricians certainly showed a big increase in percentage terms but this was from a very low base. In 1963 geriatricians accounted for $2 \%$ of hospital medical staff: in 1973 this had increased to $3.4 \%$. The number of geriatricians increased by 535 while the number of consultants in surgical specialties increased by 2040 . Numbers in psychiatry showed little more increase than those in any other specialty. Thus the changes in the accounts as measured here do not imply some hidden change in service priorities.

\section{Implications for Government policy}

Much of the present discussion about expenditure on health services suggests that governments have considerable freedom of action to vary such spending over a three- to four-year period. How far is this an illusion? The Government takes several decisions that affect the growth and long-term pattern of expenditure on the NHS.

It varies the short-term and long-term outlook for aggregate spending. Thus it has to decide whether the NHS is to get more or less growth than other forms of public spending. In practice, the NHS over the past 10 years has tended to get towards the high end of the going rate in terms of increases in public spending. The outcome has been affected by changes in relative costs. Government policy would have led to a slow, long-term increase in NHS expenditure as a proportion of national income. But the picture has been confused by an occasional jump in this proportion as a result of a sudden increase in relative pay as in 1974-5.

The Government changes the rate of entry to medical training. Expansion of the intake of medical schools has been a high priority for most governments. The numbers entering medical schools have risen from about 1500 a year at the end of the 1950 s to 3800 today with a planned intake of 4000 by the mid-1980s.

The Government makes statements of priority as among client groups. Thus over the past 10 years there have been numerous invocations of the need to spend more on the elderly, the mentally ill, and the mentally handicapped.

The present Government has stated that its policy is to devolve authority to the new health districts. Even with such decentralisation, however, there will still be certain decisions that will have to be taken by the Government. These include all the three groups of decisions listed above. They are, therefore, of more than historical interest and suggestions for improvement could still be of practical relevance.

The essential characteristic of government decision making has been the lack of relationship and the inconsistency between these various decisions. The essential result has been the lack of progress in the third group of decisions.

The actual figures suggest that the decisions on medical education set up a certain momentum in the long term. Doctors trained with a certain pattern of interest approach the service and a variety of local mechanisms then establishes a certain distribution of posts. Medical staffing together with its immediate forms of support become a first charge on finance. In bad years other forms of spending on support services and on nursing are adjusted downwards in order to allow additional spending on medical and technical staff to take place. Thus "zero growth" in 
to consult formally on the district strategic plan as a whole. There would be similar consultation on the forward part of the operational programme which the district would take into account when it subsequently revised the programme for implementation.

\section{Timetable}

(11) A chart showing the main planning activities during the year is set out in an annex to the circular.

\section{Staff consequences}

(12) Planning would be a continuous process rather than an occasional exercise. Strategic plans and annual programmes would be prepared by DHAs as part of the normal process of management and with the close involvement of managers and health care professionals responsible for the provision of services. The main job of designated planners would be to help with the preparation of plans and programmes for individual services and from them to build up the district plan or programme. DHAs would need to take responsibility for planning into account when considering management arrangements (circular $\mathrm{HC}(80) 8$ paras 22-32) and the proposed job content of appropriate posts. Even so there is likely to be a shortage of staff with particular experience or training in NHS planning. Regions would need to do what they could to assist districts, in particular on requests for analytical support in the preparation of strategic plans and in helping in the use, in the planning process, of techniques such as economic appraisal.

\section{Joint planning and finance}

(13) The arrangements for the joint planning and joint financing of services in which health authorities and local authorities have a common interest would continue on similar lines as at present (see circular HC (77) $17,{ }^{3}$ LAC(77)10) except that some local authorities will now have links with more than one DHA (circular HC(80)8 paras 19 and 20). ${ }^{2}$ Regions would include in their planning framework the joint finance assumptions to be made by districts which would form the basis of planning with the local authority through the joint consultative machinery.

(14) Further guidance would be issued

setting out the new arrangements in more detail and covering the transitional period. A replacement for the current NHS planning system manual would be considered in due course.

\section{References}

${ }^{1}$ Department of Health and Social Security. Patients first. London: HMSO, 1979.

${ }^{2}$ Department of Health and Social Security. Health service development: structure and management. HC(80)8. London: DHSS, 1980.

${ }^{3}$ Department of Health and Social Security. foint care planning: health and local authorities. HC(77)17. London: DHSS, 1977.

\section{Hospital bed closures}

It was announced in a recent Parliamentary written answer that between 1 January and 30 September 1980 decisions had been taken to close permanently hospitals or parts of hospitals which would involve the following numbers of beds:

$\begin{array}{lr}\text { Regional health authority } & \\ \text { Northern } & 22 \\ \text { Yorkshire } & 39 \\ \text { Trent } & 194 \\ \text { North Western } & 96 \\ \text { Mersey } & 71 \\ \text { West Midlands } & 44 \\ \text { North-west Thames } & 155 \\ \text { North-east Thames } & 128 \\ \text { South-east Thames } & 146 \\ \text { South-west Thames } & 762 \\ \text { East Anglia } & 10 \\ \text { Wessex } & 46\end{array}$

At 30 September 1980 the DHSS had been notified by AHAs of proposals to close permanently other hospitals or parts of hospitals involving the following numbers of beds:

$\begin{array}{lr}\text { Regional health authority } & \\ \text { Northern } & \text { NIL } \\ \text { Yorkshire } & 450 \\ \text { Trent } & 83 \\ \text { North Western } & 41 \\ \text { Mersey } & 1112 \\ \text { West Midiands } & 84 \\ \text { North-west Thames } & 243 \\ \text { North-east Thames } & 226 \\ \text { South-east Thames } & 78 \\ \text { South-west Thames } & 88 \\ \text { East Anglia } & 10 \\ \text { Wessex } & 506 \\ \text { Oxford } & 65 \\ \text { South Western } & 16\end{array}$

It is not possible to say when decisions will be taken on these proposals.

\section{Talking Point-continued from page 668}

health spending has had in the past different effects on different items in the health budget. The "economic" forces holding down spending on ancillary staff and on support functions are stronger than perhaps have been suspected before and certainly facilitate the process. Adjusted for the change in hours real inputs of ancillary staff services would have shown an actual fall in the period 1963-73.

Those who campaign for more to be spent on neglected services do so usually on the tacit understanding that it would take three to four years for any changes to be made. They assume in effect that resources can be shifted between types of care fairly quickly and easily. But they fail to take account of this underlying momentum in spending on the more technical areas of the service. ${ }^{2}$ The evidence suggests that the Government's decisions have been inconsistent. On the one hand, it has been pressing for medium-term changes in the balance of care. On the other, it has been taking longer-term decisions that militate against these intentions. These have set up-together with the effects of technological change-strong pressures to spend more on certain kinds of staff and certain kinds of materials input.

At times the Government in pursuit of a changed balance between client groups has gone beyond exhortation to special programmes and to changes in procedures. Perhaps the most notable example of this has been joint funding, by which money from NHS budgets could be used for joint projects in community care with local government. This has been relatively successful in securing a higher level of expenditure than would otherwise have been the case on these services. Here the Government was acting in an entrepreneurial way. It introduced an innovation that aroused interest and increased the local pressures towards spending in certain directions rather than in others. It may well be that such entrepreneurial activities are in practice a more effective way of reaching a goal than the general exhortation. There is plenty of room for debate on the "right" directions for change in health spending and such decisions are bound to be heavily influenced by ethical or normative considerations. I believe that taking a certain set of goals as "given" national policies has been ineffective and inconsistent.

I would like to thank Patrick D'Arifat for research assistance, staff members of the Health Economics Research Unit of the University of Aberdeen, and Professor B Abel Smith for comments.

\section{References}

1 Central Statistical Office. National accounts statistics sources and methods. London: HMSO, 1968.

${ }^{2}$ Maynard A, Walker A. Doctor manpower 1975-2000: alternative forecasts and their resource implications. Royal Commission on the NHS, Research Paper Number 4. London: HMSO, 1978.

(Accepted 16 fanuary 1981) 